\title{
Resistance to thyroid hormone: one of several defects causing reduced sensitivity to thyroid hormone
}

\author{
Samuel Refetoff
}

Forty years have elapsed since the first published description of partial refractoriness to thyroid hormone (TH) (Refetoff S et al. [1967] $J$ Clin Endocrinol Metab 27: 279-294). The three affected children, born to consanguineous parents, manifested symptoms of $\mathrm{TH}$ insufficiency but had elevated blood levels of $\mathrm{TH}$. This apparent resistance to $\mathrm{TH}(\mathrm{RTH})$ was found in other families who presented with the cardinal signs: high serum TH levels, nonsuppressed $\mathrm{TSH}$, lack of typical symptoms and signs of thyrotoxicosis and goiter. More that 2,000 affected individuals belonging to about 500 families have been identified, $85 \%$ of whom harbor mutations in the TH receptor $\beta$ gene (THRB).

$\mathrm{TH}$ receptors are nuclear transcription factors that, through $\mathrm{TH}$-binding, activate or repress specific target genes. Interference with the function of the normal $\mathrm{TH}$ receptor by mutant $\mathrm{TH}$ receptors is responsible for the dominant mode of inheritance. The recessive inheritance in the family described above was caused by complete THRB deletion. Individuals who express an identical phenotype without THRB mutations are believed to have defects in cofactors for the actions mediated by the nuclear $\mathrm{TH}$ receptor.

Recent discoveries of genetic defects that reduce the effectiveness of $\mathrm{TH}$ through altered cell membrane transport and metabolism of the hormone have broadened the definition of $\mathrm{TH}$ hyposensitivity to include all defects that could reduce the biological activity of chemically intact $\mathrm{TH}$ synthesized and secreted in normal or even excessive amounts. As "RTH" has become synonymous with the syndrome produced by reduced intracellular action of $\mathrm{TH}$, "reduced sensitivity to $\mathrm{TH}(\mathrm{RSTH})$ " has been proposed to denote genetically determined reduced effectiveness of the hormone in this broader sense. This definition of $\mathrm{TH}$ hyposensitivity syndromes was accepted by investigators at the $8^{\text {th }}$ International
This definition

of TH hypo-

sensitivity

syndromes was

accepted by

investigators

at the $8^{\text {th }}$

International

Workshop on

Resistance

to Thyroid

Hormone...

$S$ Refetoff is Professor of Medicine, Pediatrics and Genetics, at the University of Chicago, Chicago, IL, USA.

\section{Acknowledgments}

Supported in part by NIH

grants DK15070 and

RR18372.

\section{Competing interests}

The author declared an association with the

following company: Quest Diagnostics. See the article online for full details of the relationship.

www.nature.com/clinicalpractice doi:10.1038/ncpendmet0703
Workshop on Resistance to Thyroid Hormone, 9-11 October 2007, on the Azorean Island of San Miguel.

A defect in the active transport of $\mathrm{TH}$ into cells was first described in 2004. It is caused by mutations in the monocarboxylate transporter 8 gene (SLC16A2 [solute carrier family 16 , member 2]), located on the $X$ chromosome. Affected males present with severe psychomotor disorders and an unusual combination of high concentrations of active $\mathrm{TH}\left(\mathrm{T}_{3}\right)$ and low levels of an inactive metabolite (reverse $T_{3}$ ). In the next 3 years more than 100 affected individuals belonging to 28 families were identified. The psychomotor abnormalities are out of proportion to those observed in severe congenital TH deficiency. Inherited partial deficiency of the selenoprotein enzymes that generate $T_{3}$ was identified in two families in 2005. Caused by mutations in the selenocysteine insertion sequence-binding protein 2 gene (SECISBP2), it produces a variable decrease in several selenoproteins. The defect causes male infertility, but longer observation is required to reveal other consequences.

In contrast to the typical symptoms and signs of global lack or excess of TH in all body tissues, disorders that cause RSTH present as a combination of clinical and biochemical abnormalities suggesting that TH deficiency, sufficiency and excess occur at the same time. Mouse models of these defects have shed light on his paradox. Tissue differences in the level of THRB expression in RTH account for the variable responses to the elevated level of circulating hormone. In SLC16A2 defects, the variable dependence on this $\mathrm{TH}$ transporter produces differences in hormone content and action in specific tissue and cell types. As different cell types obtain active $\mathrm{TH}$ either from the circulation or through intracellular metabolism, a defect in the latter will also produce a hormonally chimeric organism. 